\title{
The Influence of $\mathrm{SiO}_{2}$ Shell on Fluorescent Properties of $\mathbf{L a F}_{3}: \mathbf{N d}^{3+} / \mathrm{SiO}_{2}$ Core/Shell Nanoparticles
}

\author{
Cui Kai, ${ }^{1,2}$ Gao Chao, ${ }^{1}$ Peng Bo, ${ }^{1,3}$ and Wei Wei ${ }^{3}$ \\ ${ }^{1}$ State Key Laboratory of Transient Optics and Photonics, Xi' an Institute of Optics and Precision Mechanics, \\ Chinese Academy of Science (CAS), Xi'an Shaanxi 710119, China \\ ${ }^{2}$ Graduate School of the Chinese Academy of Sciences, Beijing 100039, China \\ ${ }^{3}$ Institute of Advanced Materials, Nanjing University of Posts and Telecommunications, Nanjing 210003, China \\ Correspondence should be addressed to Peng Bo, bpeng@opt.ac.cn
}

Received 1 July 2010; Accepted 1 October 2010

Academic Editor: Hongchen Chen Gu

Copyright () 2010 Cui Kai et al. This is an open access article distributed under the Creative Commons Attribution License, which permits unrestricted use, distribution, and reproduction in any medium, provided the original work is properly cited.

Distinct effects of the $\mathrm{SiO}_{2}$ shell on fluorescence properties of $\mathrm{LaF}_{3}: \mathrm{Nd}^{3+} / \mathrm{SiO}_{2}$ core/shell nanoparticles were demonstrated by annealling the nanoparticles at different temperatures. Emission spectra, excitation spectra, and decay curves of the nanoparticles were measured. A significant improvement of fluorescence intensity was observed for $\mathrm{LaF}_{3}: \mathrm{Nd}^{3+} / \mathrm{SiO}_{2}$ core/shell nanoparticles annealed at $900^{\circ} \mathrm{C}$. The phenomenon is ascribed to the change of environment of $\mathrm{LaF}_{3}: \mathrm{Nd}^{3+}$ core which is imposed by $\mathrm{SiO}{ }_{2}$ shell. And the change is confirmed by the excitation spectra. It provides a useful way to improve fluorescent intensity of the $\mathrm{SiO}_{2}-\mathrm{coated}$ $\mathrm{LaF}_{3}: \mathrm{Nd}^{3+}$ nanoparticles. The lifetime for nanoparticles annealed at $900^{\circ} \mathrm{C}$ shows a slight decrease contrast with nanoparticles annealed at 400 and $600^{\circ} \mathrm{C}$. This is caused by the higher phonon energy of $\mathrm{SiO}_{2}$ than that of $\mathrm{LaF}_{3}$.

\section{Introduction}

In the past decade, the synthesis of lanthanide-doped nanoparticles has attracted a great deal of attention, since the materials are considered as potentially useful phosphors in lamps, display devices [1], components in optical telecommunication [2], new optoelectronic devices [3], and probes in biomedical imaging and detection [4]. $\mathrm{LaF}_{3}$ possessing low phonon energy, adequate thermal and environmental stability, is regarded as excellent host matrixes for performing luminescence $[5,6]$. Nanoparticles of $\mathrm{LaF}_{3}$ doped with lanthanide ions have been studied for years for their luminescence properties $[7,8]$. However, the water and organic molecules absorbed on nanoparticles noticeably hampered their optical efficiency, when the nanoparticles are dispersed into aqueous and organic environment. The $\mathrm{O}-\mathrm{H}$ and $\mathrm{C}-\mathrm{H}$ groups have a high vibration frequency and can efficiently quench the luminescence of lanthanide ions $[9,10]$. This is in particular true for the lanthanide ions emitted in the near-infrared region, like $\mathrm{Nd}^{3+}, \mathrm{Yb}^{3+}$, and $\mathrm{Er}^{3+}$ because the energy gap between excited state and ground state is small [11]. Fortunately, these problems can be overcome when an appropriate shell is grown around the lanthanide ions doped $\mathrm{LaF}_{3}$ core, and silica is usually used as a coating layer due to its high chemical stability, optical transparency, and biocompatibility [12]. $\mathrm{LaF}_{3}$ nanoparticles with different thickness of $\mathrm{SiO}_{2}$ shell were synthesized and the $\mathrm{LaF}_{3}: \mathrm{Nd}^{3+} / \mathrm{SiO}_{2}$ core/shell nanomaterials used for biological NIR probes has been reported [13, 14]. However, except the protection effect of $\mathrm{SiO}_{2}$ layer, the influence of $\mathrm{SiO}_{2}$ shell on fluorescent properties of the Lanthanide-doped $\mathrm{LaF}_{3}$ core has seldom been discussed.

In this work, To investigate the interactions between $\mathrm{SiO}_{2}$ shell and lanthanide ions doped $\mathrm{LaF}_{3}$ core, a series of $\mathrm{Nd}^{3+}$-doped $\mathrm{LaF}_{3}$ nanoparticles capped with $\mathrm{SiO}_{2}$ shell were synthesized and annealed at different temperatures. When the anneal temperature is $900^{\circ} \mathrm{C}$, spectroscopic evidence for the change of $\mathrm{LaF}_{3}$ environment created by $\mathrm{SiO}_{2}$ shell was observed. And the change of environment leads to a significant improvement of the fluorescent intensity of $\mathrm{LaF}_{3}: \mathrm{Nd}^{3+} / \mathrm{SiO}_{2}$ core/shell nanoparticles. This provides a simple and useful way to improve the fluorescent properties of lanthanide-doped $\mathrm{LaF}_{3} / \mathrm{SiO}_{2}$ core/shell nanomaterials. 


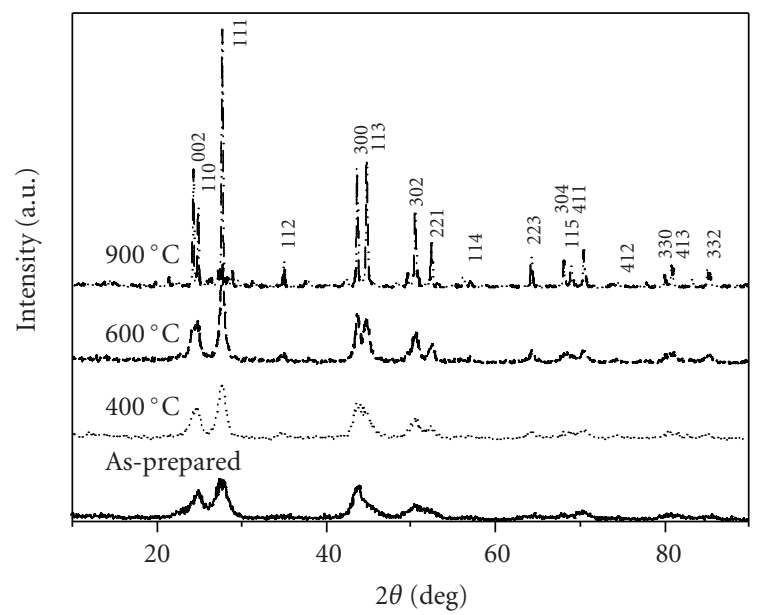

FIGURE 1: XRD patterns of $\mathrm{LaF}_{3}: \mathrm{Nd}^{3+} / \mathrm{SiO}_{2}$ core/shell nanoparticles annealed at different temperatures.

\section{Experimental}

The $\mathrm{SiO}_{2}$-coated $\mathrm{LaF}_{3}: \mathrm{Nd}^{3+}$ nanoparticles were synthesized as follows. $\mathrm{NH}_{4} \mathrm{~F}(0.44 \mathrm{~g}, 12 \mathrm{mmol})$ was dissolved in methanol $(20 \mathrm{~mL})$, and then the solution was heated to $65^{\circ} \mathrm{C}$. Another solution of $\mathrm{La}(\mathrm{NO})_{3} \cdot 6 \mathrm{H}_{2} \mathrm{O}(1.694 \mathrm{~g}, 3.89 \mathrm{mmol})$, $\mathrm{Nd}(\mathrm{NO})_{3} \cdot 6 \mathrm{H}_{2} \mathrm{O}(0.052 \mathrm{~g}, 0.11 \mathrm{mmol})$ in methanol $(10 \mathrm{~mL})$ was added dropwise to the $\mathrm{NH}_{4} \mathrm{~F}$ solution. The resulting solution was stirred at $65^{\circ} \mathrm{C}$ for $2 \mathrm{~h}$. And the $\mathrm{LaF}_{3}: \mathrm{Nd}^{3+}$ nanoparticles were collected by centrifugation. Stöber method was adopted for the $\mathrm{SiO}_{2}$ coating process. $\mathrm{LaF}_{3}: \mathrm{Nd}^{3+}$ nanopartilces $(0.5 \mathrm{~g})$ were dispersed in ethanol $(100 \mathrm{~mL})$. Then tetraethyl orthosilicate (TEOS) $(0.2 \mathrm{~mL}$, $1 \mathrm{mmol}$ ) was added dropwise to the solution. After mixing for $1 \mathrm{~min}, \mathrm{NH}_{4} \mathrm{OH}(25 \%)(3 \mathrm{~mL})$ were added in the mixture under stirring. The mixture was stirred for $3 \mathrm{~h}$ to get the as-grown sample. For better crystallinity and enhanced luminescence, the as-grown sample was annealed in the air for $4 \mathrm{~h}$ to get the final product.

The Inductively coupled plasma (ICP) analyses were carried out on a Hitachi P-4010 inductively coupled plasma emission spectrometer. X-ray diffraction (XRD) patterns were measured on a Rigaku D/max-2400 X-ray powder diffractometer. The size and morphology of nanoparticles were determined at $300 \mathrm{kV}$ by a JEOL JEM-3010 transmission electron microscope (TEM) and XL30 field-emission scanning electron microscope (SEM). Photoluminescence emission spectra were recorded on a Zolix Omini-k 300 spectrophotometer pumped by a laser diode at $800 \mathrm{~nm}$. The Fourier transform infrared (FTIR) spectra were made with a Shimadzu FT-IR 8900 spectrometer. The excitation spectra were recorded on an Edinburgh Instruments FLS920 spectrofluorimeter.

\section{Results and Discussion}

The concentrations of $\mathrm{Nd}, \mathrm{La}$, and $\mathrm{Si}$ in $\mathrm{LaF}_{3}: \mathrm{Nd}^{3+} / \mathrm{SiO}_{2}$ core/shell nanoparticles were determined to be $1.79,57.1$, and $7.93 \%$ by ICP. The XRD patterns of samples annealed at different temperatures are shown in Figure 1. When the as-prepared sample was heated at $900^{\circ} \mathrm{C}$ for $4 \mathrm{~h}$, welldefined diffraction peaks were obtained. All the peaks can be well indexed to the hexagonal $\mathrm{LaF}_{3}$ crystal structure, and no trace of other characteristic peaks were observed. The TEM and SEM images provide direct information about the sizes and typical shapes of the nanoparticles. Figure 2 illustrates the representative TEM and SEM images of the $\mathrm{LaF}_{3}: \mathrm{Nd}^{3+}$ nanoparticles and those coated of $\mathrm{SiO}_{2}$ shells. The bare $\mathrm{LaF}_{3}: \mathrm{Nd}^{3+}$ sample contains nanoparticles with an average size of $8 \mathrm{~nm}$. After coating the $\mathrm{SiO}_{2}$ shell, it is clearly observed that the particles have a core-shell structure and the silica shell thickness is about $5-7 \mathrm{~nm}$. When the $\mathrm{LaF}_{3}: \mathrm{Nd}^{3+} / \mathrm{SiO}_{2}$ nanoparticles were annealed at $900^{\circ} \mathrm{C}$ for $4 \mathrm{~h}$, the morphology of the sample aggregates with a size from 30-60 $\mathrm{nm}$, and the SEM image (Figure 2(d)) showed that the annealed $\mathrm{LaF}_{3}: \mathrm{Nd}^{3+} / \mathrm{SiO}_{2}$ nanoparticles consists of spherical particles with a size between $50-150 \mathrm{~nm}$.

The FTIR spectra of $\mathrm{LaF}_{3}: \mathrm{Nd}^{3+} / \mathrm{SiO}_{2}$ core/shell nanoparticles are presented in Figure 3. Strong vibrational absorption bands at $3400-3600$ and $1350-1600 \mathrm{~cm}^{-1}$ were observed in as-prepared sample, which correspond to $\mathrm{O}-\mathrm{H}$ mode. So the physically adsorbed solvent and $\mathrm{O}-\mathrm{H}$ groups on the asprepared nanoparticles are still not removed. Whereas for the nanoparticles annealed at $400^{\circ} \mathrm{C}$, the former absorption peaks show a great decrease. When the anneal temperature raised to $900^{\circ} \mathrm{C}$, the absorption peaks of $\mathrm{O}-\mathrm{H}$ mode completely disappeared. Thus, the nonradiative vibrational excitation of $\mathrm{Nd}^{3+}$ in the nanoparticles created by $\mathrm{O}-\mathrm{H}$ and $\mathrm{C}-\mathrm{H}$ groups can be excluded.

Figure 4 shows the room temperature emission spectra of $\mathrm{LaF}_{3}: \mathrm{Nd}^{3+} / \mathrm{SiO}_{2}$ core/shell and $\mathrm{LaF}_{3}: \mathrm{Nd}^{3+}$ nanoparticles under excitation at $808 \mathrm{~nm}$. The emission lines centered at 880,1060 , and $1330 \mathrm{~nm}$ correspond to the transitions from ${ }^{4} \mathrm{~F}_{3 / 2}$ to ${ }^{4} \mathrm{I}_{9 / 2},{ }^{4} \mathrm{I}_{11 / 2}$, and ${ }^{4} \mathrm{I}_{13 / 2}$, respectively [15]. For $\mathrm{LaF}_{3}: \mathrm{Nd}^{3+} / \mathrm{SiO}_{2}$ core/shell nanoparticles as-prepared and annealed at 400 and $600^{\circ} \mathrm{C}$, the emission pattern is similar with that of $\mathrm{LaF}_{3}: \mathrm{Nd}^{3+}$ nanoparticles in both the peak positions and shapes, which means that the $\mathrm{SiO}_{2}$ shell have minimal effect on $\mathrm{LaF}_{3}: \mathrm{Nd}^{3+}$ core. However, when the annealed temperature is $900^{\circ} \mathrm{C}$, emission spectra of the $\mathrm{LaF}_{3}: \mathrm{Nd}^{3+} / \mathrm{SiO}_{2}$ core/shell nanoparticles show a very unusual manner. (1) Their fluorescence intensity show a great increase compared with that of the $\mathrm{LaF}_{3}: \mathrm{Nd}^{3+} / \mathrm{SiO}_{2}$ core/shell nanoparticles annealed at $600^{\circ} \mathrm{C}$. (2) The strongest emission line for ${ }^{4} \mathrm{~F}_{3 / 2} \rightarrow{ }^{4} \mathrm{I}_{11 / 2}$ transition peaking at $1073 \mathrm{~nm}$ are redshifted by about $17 \mathrm{~nm}$ contrasted with that of nanoparticles annealed at $600^{\circ} \mathrm{C}(1056 \mathrm{~nm})$. (3) The ${ }^{4} \mathrm{~F}_{3 / 2} \rightarrow{ }^{4} \mathrm{I}_{9 / 2}$ and ${ }^{4} \mathrm{~F}_{3 / 2} \rightarrow{ }^{4} \mathrm{I}_{13 / 2}$ emission of $\mathrm{LaF}_{3}: \mathrm{Nd}^{3+} / \mathrm{SiO}_{2}$ core/shell nanoparticles annealed at $900^{\circ} \mathrm{C}$ have remarkable Stark splittings which have not been found in other samples. In contrast, emission spectrum of $900^{\circ} \mathrm{C}$ annealed $\mathrm{LaF}_{3}: \mathrm{Nd}^{3+}$ nanoparticles which have no $\mathrm{SiO}_{2}$ shell has also been recorded, and is shown in Figure 4(b). The fluorescence intensity is only about $1 / 5$ compared with that of $\mathrm{LaF}_{3}: \mathrm{Nd}^{3+} / \mathrm{SiO}_{2}$ core/shell nanoparticles annealed at $900^{\circ} \mathrm{C}$, the ${ }^{4} \mathrm{~F}_{3 / 2} \rightarrow{ }^{4} \mathrm{I}_{11 / 2}$ emission is peaking at about $1058 \mathrm{~nm}$, and no emission lines have Stark splittings. The results mean, for $\mathrm{LaF}_{3}: \mathrm{Nd}^{3+} / \mathrm{SiO}_{2}$ core/shell nanoparticles, that the influence 


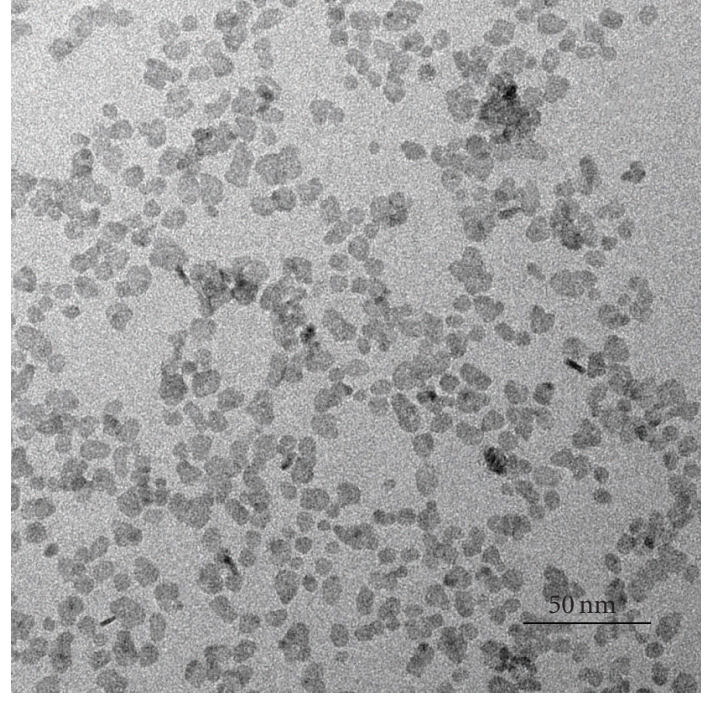

(a)

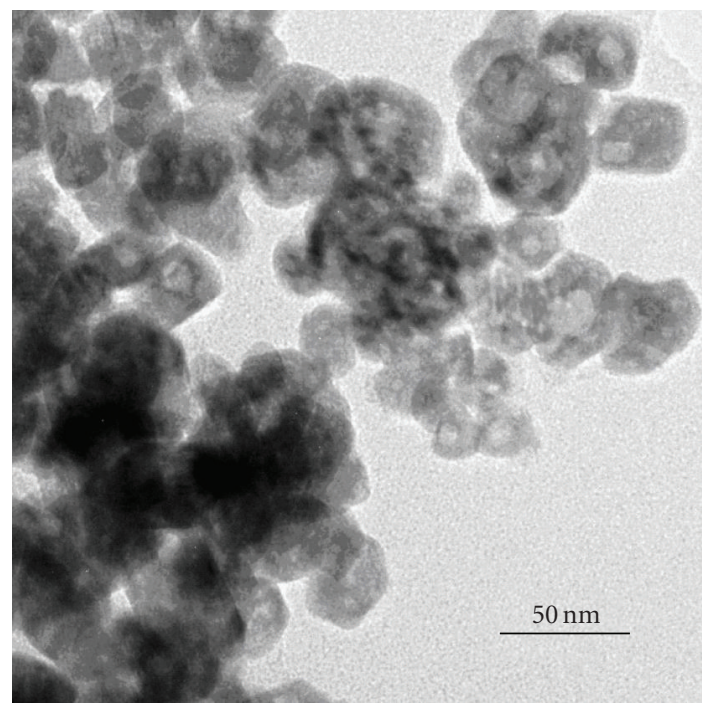

(c)

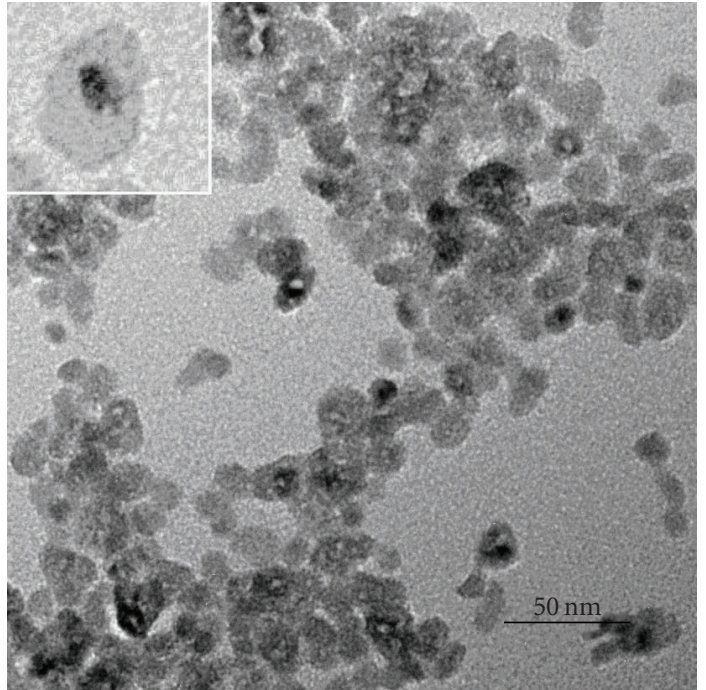

(b)

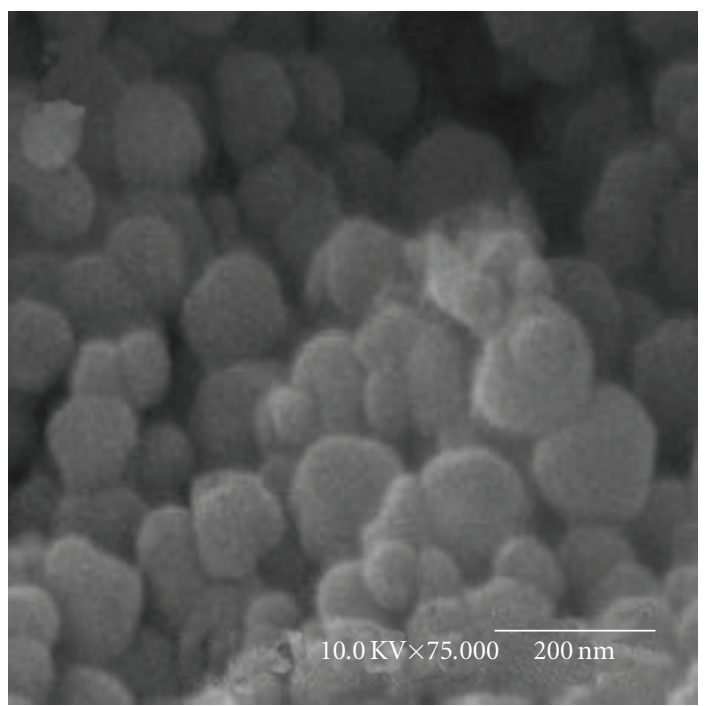

(d)

Figure 2: TEM images of (a) $\mathrm{LaF}_{3}: \mathrm{Nd}^{3+}$, (b) $\mathrm{LaF}_{3}: \mathrm{Nd}^{3+} / \mathrm{SiO}_{2}$, (c) $\mathrm{LaF}_{3}: \mathrm{Nd}^{3+} / \mathrm{SiO}_{2}$ annealed at $900^{\circ} \mathrm{C}, \mathrm{SEM}$ image of $(\mathrm{d}) \mathrm{LaF}_{3}: \mathrm{Nd}^{3+} / \mathrm{SiO} 2$ annealed at $900^{\circ} \mathrm{C}$.

of $\mathrm{SiO}_{2}$ shell has become clearly when the anneal temperature is $900^{\circ} \mathrm{C}$, and the remarkable improvement of fluorescence intensity is caused by the $\mathrm{SiO}_{2}$ shell.

To get more information on the functions of $\mathrm{SiO}_{2}$ shell, the excitation spectra by monitoring the ${ }^{4} \mathrm{~F}_{3 / 2} \rightarrow$ ${ }^{4} \mathrm{I}_{11 / 2}$ emission in $\mathrm{LaF}_{3}: \mathrm{Nd}^{3+} / \mathrm{SiO}_{2}$ core/shell and $\mathrm{LaF}_{3}: \mathrm{Nd}^{3+}$ nanoparticles annealed at $900^{\circ} \mathrm{C}$ are compared in Figure 5. The spectra displays well-resolved lines, centered at 328, 352, $430,472,519,578.9,737,801$, and $881 \mathrm{~nm}$ corresponding to the direct excitation of $\mathrm{Nd}^{3+}$ from ${ }^{4} \mathrm{I}_{9 / 2}$ to the higher excited states: ${ }^{2} \mathrm{D}_{5 / 2},{ }^{2} \mathrm{P}_{1 / 2},{ }^{4} \mathrm{G}_{11 / 2},{ }^{2} \mathrm{~K}_{15 / 2}+{ }^{2} \mathrm{D}_{3 / 2}+{ }^{2} \mathrm{G}_{9 / 2}$, ${ }^{2} \mathrm{~K}_{13 / 2}+{ }^{4} \mathrm{G}_{7 / 2}+{ }^{4} \mathrm{G}_{9 / 2},{ }^{2} \mathrm{G}_{7 / 2}+{ }^{2} \mathrm{G}_{5 / 2},{ }^{2} \mathrm{H}_{11 / 2},{ }^{4} \mathrm{~F}_{9 / 2},{ }^{4} \mathrm{~S}_{3 / 2}+{ }^{4} \mathrm{~F}_{7 / 2}$, ${ }^{4} \mathrm{~F}_{5 / 2}+{ }^{2} \mathrm{H}_{9 / 2}$, and ${ }^{4} \mathrm{~F}_{3 / 2}$. Interestingly, remarkable differences are observed in excitation spectra of the two samples. As shown in the inset of Figure 5, the shape of peaks for ${ }^{4} \mathrm{I}_{9 / 2} \rightarrow{ }^{2} \mathrm{P}_{1 / 2}$ transition are different between the two nanoparticles, and the lines for ${ }^{4} \mathrm{I}_{9 / 2} \rightarrow{ }^{4} \mathrm{~S}_{3 / 2}+{ }^{4} \mathrm{~F}_{7 / 2}$, and ${ }^{4} \mathrm{~F}_{5 / 2}+{ }^{2} \mathrm{H}_{9 / 2}$ transitions of $\mathrm{LaF}_{3}: \mathrm{Nd}^{3+} / \mathrm{SiO}_{2}$ core/shell nanoparticles are much broader compared with that of $\mathrm{LaF}_{3}: \mathrm{Nd}^{3+}$ nanoparticles. The changes of excitation spectra mean that the environment of $\mathrm{LaF}_{3}: \mathrm{Nd}^{3+}$ is different for the two nanoparticles. The Stark splittings of ${ }^{4} \mathrm{~F}_{3 / 2} \rightarrow{ }^{4} \mathrm{I}_{9 / 2}$ and ${ }^{4} \mathrm{~F}_{3 / 2} \rightarrow{ }^{4} \mathrm{I}_{13 / 2}$ emission for $\mathrm{LaF}_{3}: \mathrm{Nd}^{3+} / \mathrm{SiO}_{2}$ core/shell nanoparticles annealed at $900^{\circ} \mathrm{C}$ also confirmed the change. In previous reports, the phenomena were often caused by the host matrixes or surfactants [15]. In this work, for $\mathrm{SiO}_{2}$ shell and $\mathrm{LaF}_{3}$ core have not the same lattice structures, the shell could bring a noncentrosymmetric environment of the $\mathrm{LaF}_{3}: \mathrm{Nd}^{3+}$ core [16]. And the new noncentrosymmetric environment causes a significant improvement of fluorescent intensity of $\mathrm{LaF}_{3}: \mathrm{Nd}^{3+} / \mathrm{SiO}_{2}$ core/shell nanoparticles [17]. 


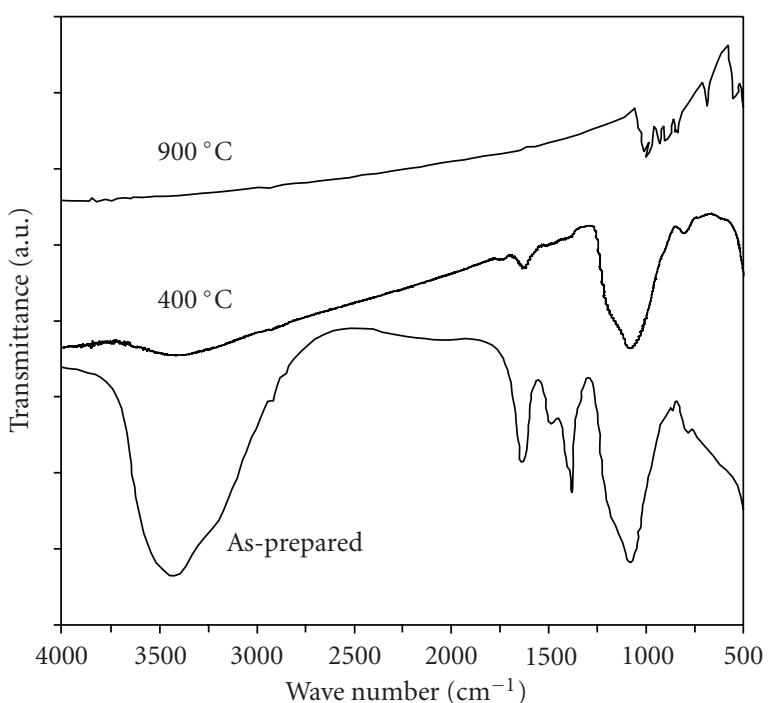

FIGURE 3: FTIR spectra of $\mathrm{LaF}_{3}: \mathrm{Nd}^{3+} / \mathrm{SiO}_{2}$ core/shell nanoparticles annealed at different temperatures.

TABLE 1: Lifetimes of nanoparticles annealed at different temperatures.

\begin{tabular}{lcc}
\hline Nanoparticles & $\begin{array}{r}\text { Annealed temperature } \\
\left({ }^{\circ} \mathrm{C}\right)\end{array}$ & $\begin{array}{c}\text { Lifetime } \\
(\mu \mathrm{s})\end{array}$ \\
\hline & 400 & 159 \\
$\mathrm{LaF}_{3}: \mathrm{Nd}^{3+} / \mathrm{SiO}_{2}$ core/shell & 600 & 156 \\
& 900 & 148 \\
$\mathrm{LaF}_{3}: \mathrm{Nd}^{3+}$ & 900 & 197 \\
\hline
\end{tabular}

To have a further investigation of influence of the $\mathrm{SiO}_{2}$ shell on $\mathrm{LaF}_{3}: \mathrm{Nd}^{3+}$ core, fluorescent decay curves of $\mathrm{LaF}_{3}: \mathrm{Nd}^{3+} / \mathrm{SiO}_{2}$ core/shell nanoparticles were measured by monitoring the ${ }^{4} \mathrm{~F}_{3 / 2} \rightarrow{ }^{4} \mathrm{I}_{11 / 2}$ emission at about $1060 \mathrm{~nm}$. As shown in Table 1. For as-prepared nanoparticles, the lifetime is very difficult to be detected due to the presence of a large amount of $\mathrm{O}-\mathrm{H}$ groups. When the nanoparticles were annealed at $400^{\circ} \mathrm{C}$, the lifetime is $159 \mu$ s. Surprisingly, with a further rising of the anneal temperature, the lifetimes show a slight decrease. When annealed at 600 and $900^{\circ} \mathrm{C}$, the lifetimes are $156 \mu$ s and $148 \mu \mathrm{s}$, respectively. However, for $900^{\circ} \mathrm{C}$ annealed $\mathrm{LaF}_{3}: \mathrm{Nd}^{3+}$ nanoparticles which have no $\mathrm{SiO}_{2}$ shell, the lifetime is $196 \mu$ s. It can be deduced that the lifetimes decrease in $\mathrm{LaF}_{3}: \mathrm{Nd}^{3+} / \mathrm{SiO}_{2}$ core/shell nanoparticles is not caused by the $\mathrm{LaF}_{3}: \mathrm{Nd}^{3+}$ core itself. In general, there are two factors that could affect radiative lifetime of $\mathrm{Nd}^{3+}$ in nanoparticles. (1) The existence of $\mathrm{O}-\mathrm{H}$ groups and impurity on nanoparticles surfaces which could effectively reduce the lifetime of $\mathrm{Nd}^{3+}$; (2) vibrational energies of host matrix. For our samples, the difference is just the anneal temperature. For $\mathrm{LaF}_{3}: \mathrm{Nd}^{3+} / \mathrm{SiO}_{2}$ core/shell nanoparticles annealed at $900^{\circ} \mathrm{C}$, the effect of $\mathrm{O}-\mathrm{H}$ groups can be obviated (Figure 3 ) and the $\mathrm{LaF}_{3}$ host has a good crystallinity (Figure 1).

The $\mathrm{LaF}_{3}: \mathrm{Nd}^{3+} / \mathrm{SiO}_{2}$ core/shell nanoparticles were synthesized in two steps. In as-prepared nanoparticles, $\mathrm{SiO}_{2}$ shell

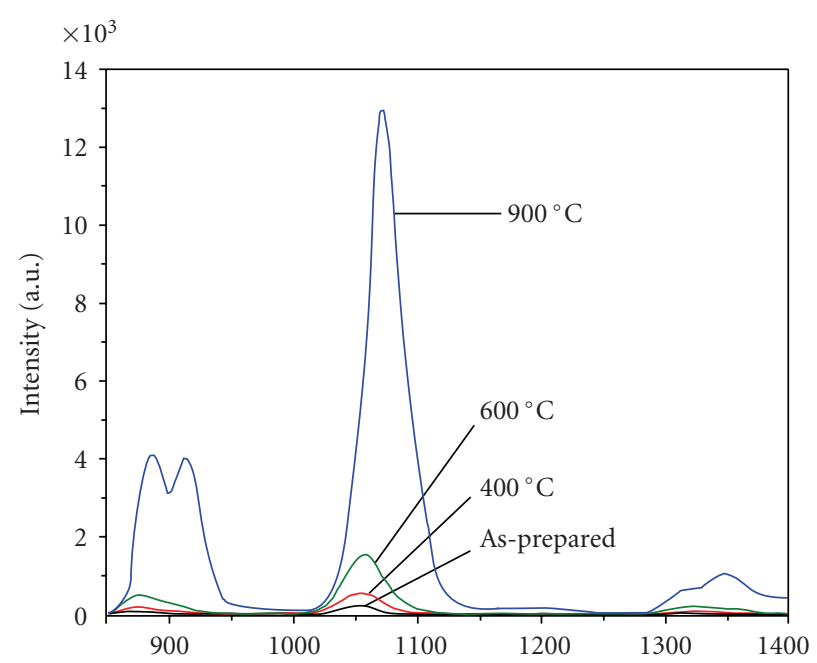

(a)

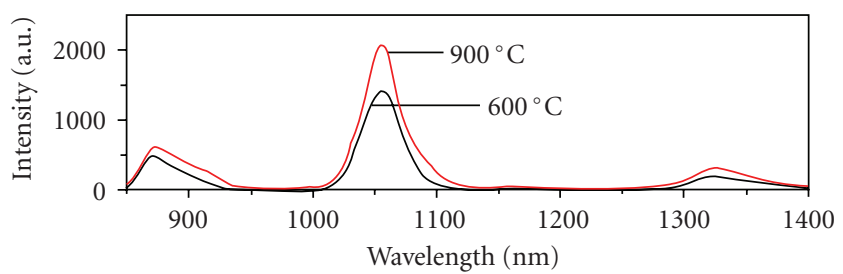

(b)

Figure 4: Emission spectra of nanoparticles annealed at different temperatures: (a) $\mathrm{LaF}_{3}: \mathrm{Nd}^{3+} / \mathrm{SiO}_{2}$, (b) $\mathrm{LaF}_{3}: \mathrm{Nd}^{3+}$.

is just coated on $\mathrm{LaF}_{3}: \mathrm{Nd}^{3+}$ core and interaction between the two parts is very weak. When the anneal temperature is $400^{\circ} \mathrm{C}$, most solvent remained on nanoparticles is removed. Thus its lifetime is of $159 \mu \mathrm{s}$. When the anneal temperature was raised to $900^{\circ} \mathrm{C}$, the interaction between $\mathrm{SiO}_{2}$ shell and $\mathrm{LaF}_{3}: \mathrm{Nd}^{3+}$ core increases. Since the phonon energy of $\mathrm{SiO}_{2}$ $\left(1100 \mathrm{~cm}^{-1}\right)$ is higher than that of $\mathrm{LaF}_{3}\left(350 \mathrm{~cm}^{-1}\right)$ and the nanoparticles have a larger surface-to-core ratio [16], lifetime of $\mathrm{Nd}^{3+}$ near or on the surfaces of nanoparticles is slightly shorter than that of $\mathrm{Nd}^{3+}$ within the core structures and the measured lifetime of $\mathrm{LaF}_{3}: \mathrm{Nd}^{3+} / \mathrm{SiO}_{2}$ core/shell nanoparticles is decreased.

\section{Conclusions}

To summarize, we have shown that, for the $\mathrm{SiO}_{2}$-coated $\mathrm{LaF}_{3}: \mathrm{Nd}^{3+}$ nanoparticles, the $\mathrm{SiO}_{2}$ shell has an interesting influence on their $\mathrm{LaF}_{3}$ core. When the anneal temperature is $900^{\circ} \mathrm{C}$, the change of environment of $\mathrm{LaF}_{3}: \mathrm{Nd}^{3+}$ core caused by $\mathrm{SiO}_{2}$ shell has become obvious. As a result, Stark splittings of ${ }^{4} \mathrm{~F}_{3 / 2} \rightarrow{ }^{4} \mathrm{I}_{9 / 2}$ and ${ }^{4} \mathrm{~F}_{3 / 2} \rightarrow{ }^{4} \mathrm{I}_{13 / 2}$ transition peaks and the redshift of ${ }^{4} \mathrm{~F}_{3 / 2} \rightarrow{ }^{4} \mathrm{I}_{11 / 2}$ transition peak were observed in their emission spectrum. The fluorescent intensity of $\mathrm{LaF}_{3}: \mathrm{Nd}^{3+} / \mathrm{SiO}_{2}$ core/shell nanoparticles also has a great improvement, which can be very beneficial for applications. 


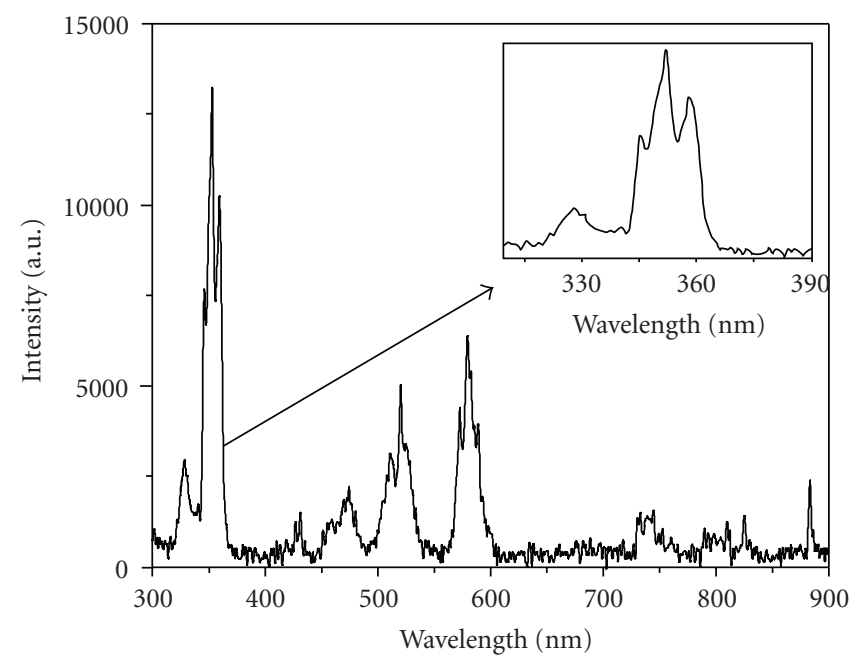

(a)

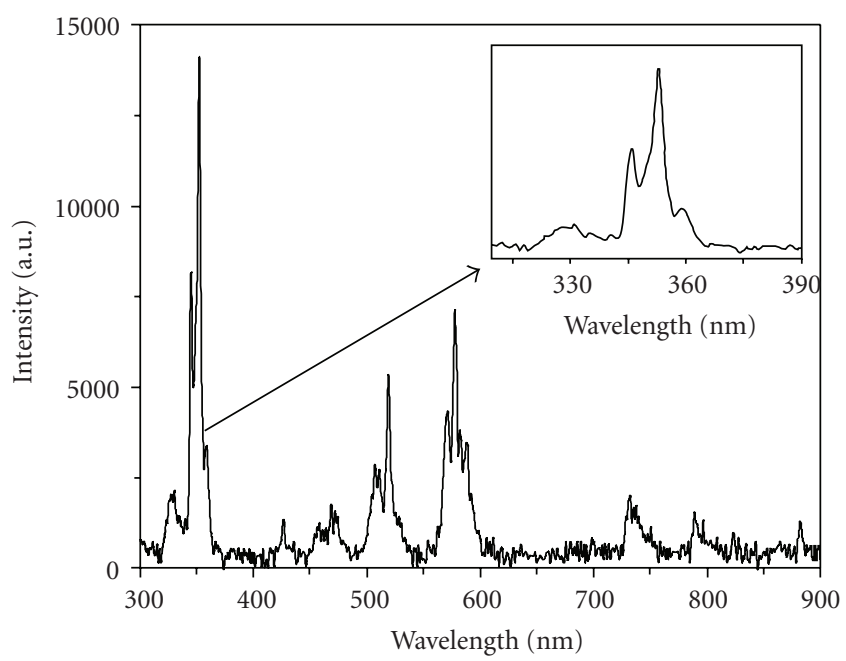

(b)

FIgURE 5: Excitation spectra of nanoparticles annealed at $900^{\circ} \mathrm{C}$ : (a) $\mathrm{LaF}_{3}: \mathrm{Nd}^{3+} / \mathrm{SiO}_{2}$, (b) $\mathrm{LaF}_{3}: \mathrm{Nd}^{3+}$.

\section{Acknowledgments}

This work was financially supported by the National Natural Science Foundation of China (no. 10876009) and one Hundred Talents Programs of the Chinese Academy of Sciences.

\section{References}

[1] H. Song, B. Chen, B. Sun, J. Zhang, and S. Lu, "Ultraviolet light-induced spectral change in cubic nanocrystalline $\mathrm{Y}_{2} \mathrm{O}_{3}: \mathrm{Eu}^{3+}$," Chemical Physics Letters, vol. 372, no. 3-4, pp. 368-372, 2003.

[2] M. Nishi, S. Tanabe, M. Inoue, M. Takahashi, K. Fujita, and K. Hirao, "Optical-telecommunication-band fluorescence properties of $\mathrm{Er}^{3+}$-doped YAG nanocrystals synthesized by glycothermal method," Optical Materials, vol. 27, no. 4, pp. 655-662, 2005.

[3] Y. Pan, Q. Su, H. Xu et al., "Synthesis and red luminescence of $\mathrm{Pr}^{3+}$-doped $\mathrm{CaTiO}_{3}$ nanophosphor from polymer precursor," Journal of Solid State Chemistry, vol. 174, no. 1, pp. 69-73, 2003.

[4] F. Wang, W. B. Tan, Y. Zhang, X. Fan, and M. Wang, "Luminescent nanomaterials for biological labelling," Nanotechnology, vol. 17, no. 1, pp. R1-R13, 2006.

[5] X.-J. Wang, S. H. Huang, R. Reeves et al., "Studies of the spectroscopic properties of $\mathrm{Pr}^{3+}$ doped $\mathrm{LaF}_{3}$ nanocrystals/glass," Journal of Luminescence, vol. 94-95, pp. 229-233, 2001.

[6] S. Tanabe, H. Hayashi, T. Hanada, and N. Onodera, "Fluorescence properties of $\mathrm{Er}^{3+}$ ions in glass ceramics containing $\mathrm{LaF}_{3}$ nanocrystals," Optical Materials, vol. 19, no. 3, pp. 343-349, 2002.

[7] J. Wang, J. Hu, D. Tang, X. Liu, and Z. Zhen, “Oleic acid (OA)modified $\mathrm{LaF}_{3}: \mathrm{Er}, \mathrm{Yb}$ nanocrystals and their polymer hybrid materials for potential optical-amplification applications," Journal of Materials Chemistry, vol. 17, no. 16, pp. 1597-1601, 2007.

[8] D. Pi, F. Wang, X. Fan, M. Wang, and Y. Zhang, "Luminescence behavior of $\mathrm{EU}^{3+}$ doped $\mathrm{LaF}_{3}$ nanoparticles," Spectrochimica Acta A, vol. 61, no. 11-12, pp. 2455-2459, 2005.
[9] W Dew, Harrocks Jr., and D. R. Sudnick, "Lanthanide ion luminescence probes of the structure of biological macromolecules," Accounts of Chemical Research, vol. 14, no. 12, pp. 384-392, 1981.

[10] S. T. Frey, C. A. Chang, J. F. Carvalho et al., "Characterization of lanthanide complexes with a series of amidebased macrocycles, potential MRI contrast agents, using $\mathrm{EU}^{3+}$ luminescence spectroscopy and molecular mechanics," Inorganic Chemistry, vol. 33, no. 13, pp. 2882-2889, 1994.

[11] J. W. Stouwdam, G. A. Hebbink, J. Huskens, and F. C. J. M. Van Veggel, "Lanthanide-doped nanoparticles with excellent luminescent properties in organic media," Chemistry of Materials, vol. 15, no. 24, pp. 4604-4616, 2003.

[12] L. M. Liz-Marzán and P. Mulvaney, "The assembly of coated nanocrystals," Journal of Physical Chemistry B, vol. 107, no. 30, pp. 7312-7326, 2003.

[13] Y. Wang, W. Qin, J. Zhang, C. Cao, S. Lü, and X. Ren, "Photoluminescence of colloidal $\mathrm{YVO}_{4}: \mathrm{Eu} / \mathrm{SiO}_{2}$ core/shell nanocrystals," Optics Communications, vol. 282, no. 6, pp. 1148-1153, 2009.

[14] X.-F. Yu, L.-D. Chen, M. Li et al., "Highly efficient fluorescence of $\mathrm{NdF}_{3} / \mathrm{SiO}_{2}$ core/shell nanoparticles and the applications for in vivo NIR detection," Advanced Materials, vol. 20, no. 21, pp. 4118-4123, 2008.

[15] J. W. Stouwdam and F. C. J. M. Van Veggel, "Near-infrared emission of redispersible $\mathrm{Er}^{3+}, \mathrm{Nd}^{3+}$, and $\mathrm{Ho}^{3+}$ doped $\mathrm{LaF}_{3}$ nanoparticles," Nano Letters, vol. 2, no. 7, pp. 733-737, 2002.

[16] Q. Lü, A. Li, F. Guo, L. Sun, and L. Zhao, "The two-photon excitation of $\mathrm{SiO}_{2}$-coated $\mathrm{Y}_{2} \mathrm{O}_{3}: \mathrm{Eu}^{3+}$ nanoparticles by a nearinfrared femtosecond laser," Nanotechnology, vol. 19, no. 20, Article ID 205704, 2008.

[17] H.-X. Mai, Y.-W. Zhang, R. Si et al., "High-quality sodium rare-earth fluoride nanocrystals: controlled synthesis and optical properties," Journal of the American Chemical Society, vol. 128, no. 19, pp. 6426-6436, 2006. 

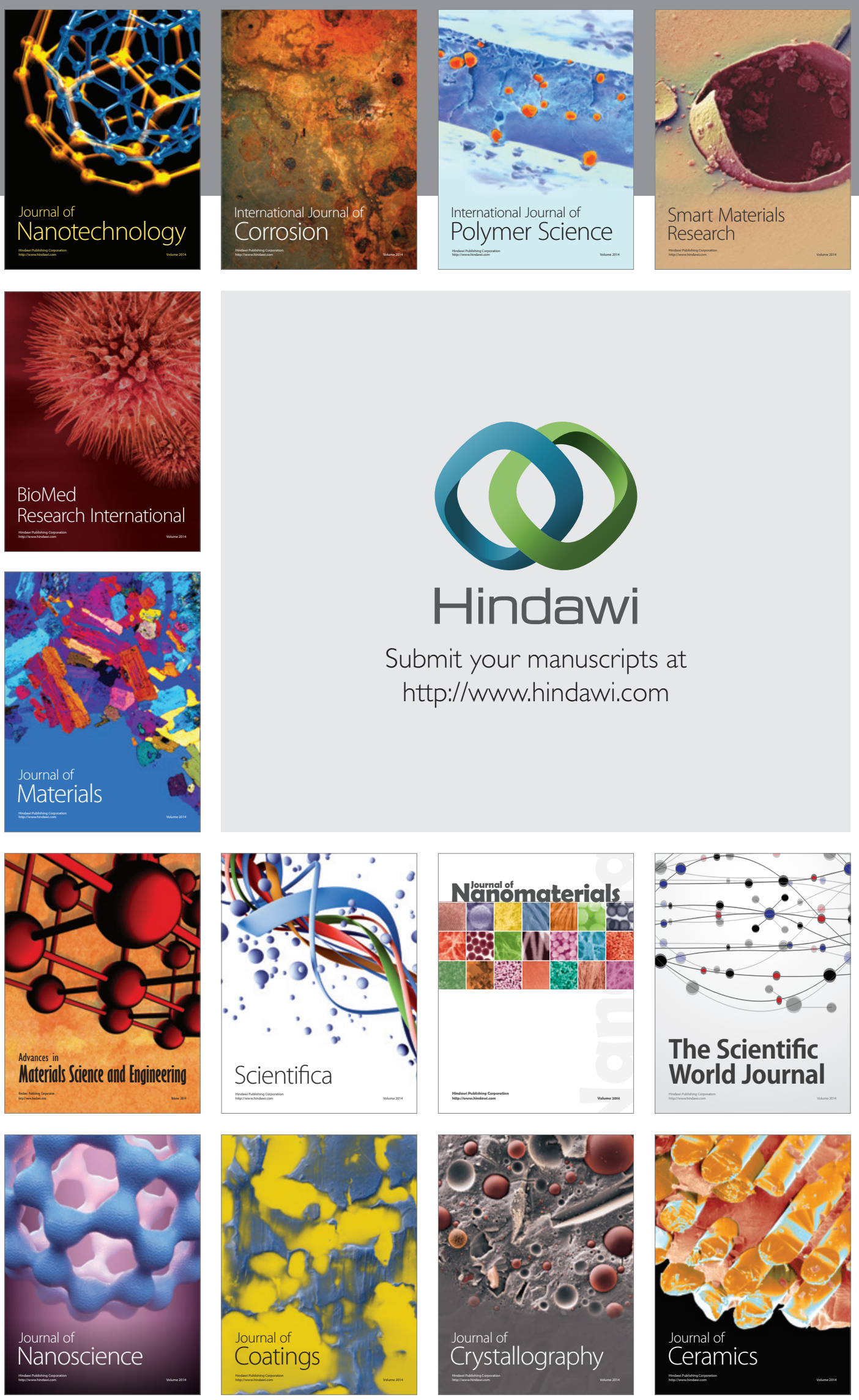

The Scientific World Journal

Submit your manuscripts at

http://www.hindawi.com

\section{World Journal}

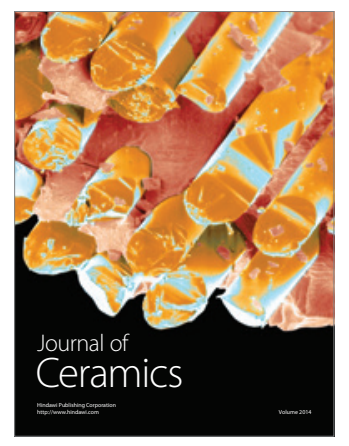

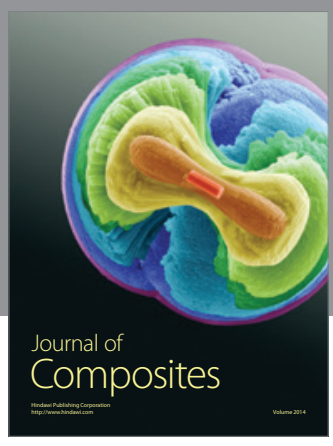
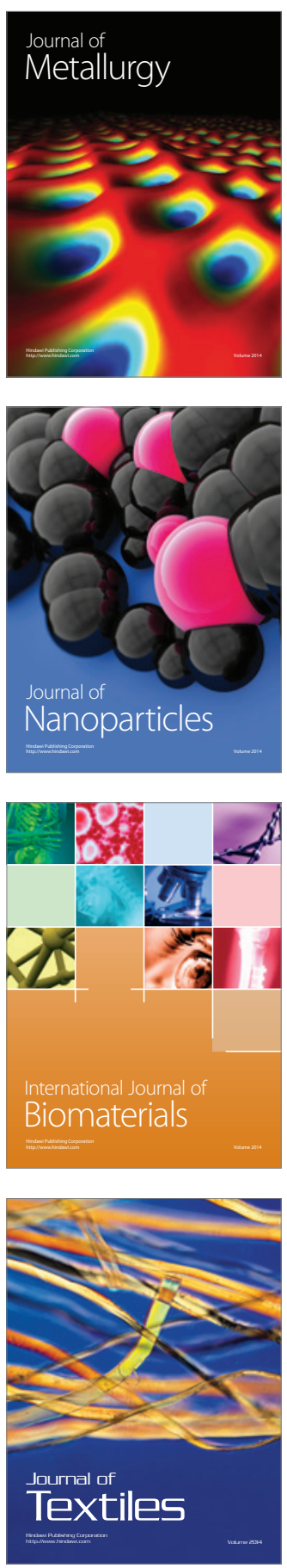